\title{
End systolic volume and scar burden are incremental and independent predictors of survival in patients with severe ischemic cardiomyopathy
}

\author{
Deborah Kwon*, Rory Hachamovitch, Zoran B Popovic, Scott D Flamm, Thomas Marwick
}

From 15th Annual SCMR Scientific Sessions

Orlando, FL, USA. 2-5 February 2012

\section{Background}

Scar burden has been shown to be an independent predictor of mortality in patients with severe ischemic cardiomyopathy (ICM). However, it is unclear how both scar burden and end systolic volume (ESV) impact outcomes in patients with severe ischemic (ICM).

\section{Purpose}

In patients with severe ICM, we sought to assess the association of ESV and scar burden with outcomes in severe ICM.

\section{Methods}

450 patients with $>70 \%$ stenosis in $\geq 1$ epicardial coronary artery $(75 \%$ men, median age 63 years, median LV ejection fraction (EF) 22\%, median ESVi $106 \mathrm{ml}$, median scar \% of $29 \%$ ) underwent delayed hyperenhancementMRI (Siemens 1.5-T scanner, Erlangen, Germany) between 2003-2007. CMR evaluation included long and short axis assessment of LV function on balanced steady state free precession images along with assessment of myocardial scar (on phase-sensitive inversion recovery DHE-CMR sequence 10-20 minutes after injection of $0.2 \mathrm{mmol} / \mathrm{kg}$ of Gadolinium dimenglumine). Scar was identified as regions of interest $>2$ SD above normal myocardium. LV scar was was recorded as a percentage of the total myocardium and transmural extent $(0=$ none, $1=1-25 \%, 2=26-50 \%, 3=51-75 \%$, and $4=>$ $75 \%)$. Total scar score was determined from the summed scar score of 17 segments per patient divided by 17 . Cox proportional hazards survival modeling,

Cleveland Clinic, Cleveland, OH, USA using a primary end-point of all-cause mortality, was used to risk-adjust comparisons.

\section{Results}

Over a follow-up of up to 9 years [mean 5.75years], 186 deaths occurred. Survival analysis revealed that after adjusting for subsequent CABG, sex, age, and mitral valve procedures, indexed ESV (ESVi) $(\chi 219.25, \mathrm{p}=$ $0.0017)$ and scar $\%(\chi 225.97, \mathrm{p}=<0.001)$ were independent and additive predictors of all cause mortality. Higher ESVI, in the setting of higher scar \%, resulted in significantly worse mortality than in patients with higher scar \% and lower ESVi. On the other hand, higher ESVi did not significantly impact survival in patients with minimal or no myocardial scar. (See Figure 1).

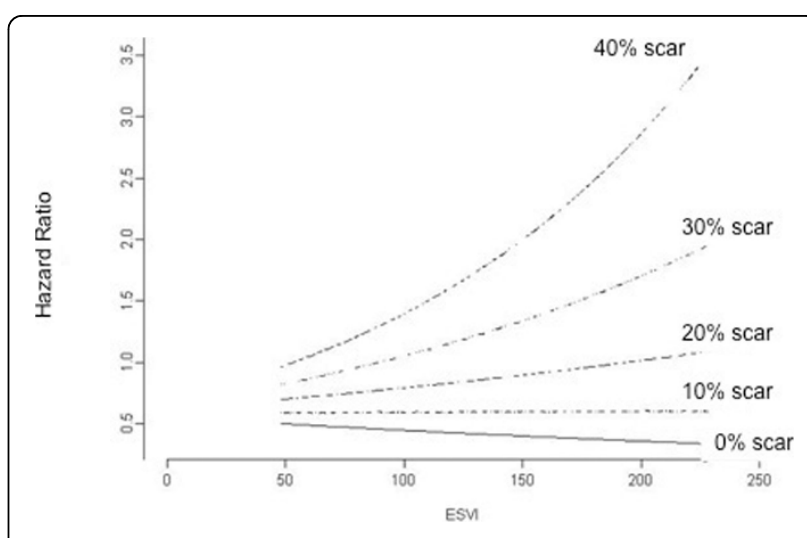

Figure 1

@ 2012 Kwon et al; licensee BioMed Central Ltd. This is an open access article distributed under the terms of the Creative Commons 


\section{Conclusions}

ESVi and scar burden provide independent and incremental prognostic value in patients with severe ICM. Prognosis should not be considered by scar burden in isolation.

\section{Funding}

None.

Published: 1 February 2012

doi:10.1186/1532-429X-14-S1-016

Cite this article as: Kwon et al:: End systolic volume and scar burden are incremental and independent predictors of survival in patients with severe ischemic cardiomyopathy. Journal of Cardiovascular Magnetic Resonance 2012 14(Suppl 1):016.

Submit your next manuscript to BioMed Central and take full advantage of:

- Convenient online submission

- Thorough peer review

- No space constraints or color figure charges

- Immediate publication on acceptance

- Inclusion in PubMed, CAS, Scopus and Google Scholar

- Research which is freely available for redistribution

Submit your manuscript at www.biomedcentral.com/submit 